\title{
Confirmatory factor analysis of the Inventory of Statements About Self-injury in a Spanish clinical sample
}

\author{
Sandra Pérez ${ }^{1}$ (1) | Joaquín García-Alandete ${ }^{2}$ (1) | \\ Montserrat Cañabate ${ }^{3,4}$ Jose H. Marco ${ }^{5}$
}

${ }^{1}$ Department of Personality, Assessment, and Psychotherapeutic Interventions, Universidad Católica de Valencia San Vicente Mártir, Valencia, Spain

${ }^{2}$ Department of Neuropsychobiology, Methodology, and Basic and Social Psychology, Universidad Católica de Valencia San Vicente Mártir, Valencia, Spain

${ }^{3}$ School of Doctorate, Universidad Católica de Valencia San Vicente Mártir, Valencia, Spain

${ }^{4}$ Department of Nursing, Universidad CEU Cardenal Herrera, Castellón, Spain

${ }^{5}$ Department of Personality, Assessment, and Psychological Treatments, Faculty of Psychology, Universidad de Valencia, Valencia, Spain

\section{Correspondence}

Sandra Pérez, Department of Personality, Assessment and Therapeutic Interventions, Catholic University of Valencia, C/ Guillem de Castro, 175, Valencia 46008, Spain.

Email: mariasandra.perez@ucv.es

\begin{abstract}
Objectives: The main aim of the present study was to confirm the two-factor structure of the Inventory of Statements About Self-injury- Part II (ISAS-II), analyze its psychometric properties and test-retest reliability of Parts I and II of the ISAS.
\end{abstract}

Method: The sample was composed of 355 Spanish participants diagnosed with eating disorders or borderline personality disorder (mean age 27.89, standard deviation = 13.31; 315 women, 40 men). Two models proposed for the ISAS-II were analyzed by means of confirmatory factorial analysis.

Results: A two-factor model was confirmed, and a model with self-care included in the intrapersonal factor was preferable. The ISAS-II showed positive correlations with emotional dysregulation. Test-retest reliability showed statistically significant correlations at 7 months ( $n=123)$.

Conclusion: The ISAS-II is a valid instrument to assess nonsuicidal self-injury in Spanish populations, making it possible to assess these behaviors, which require valid and reliable measures worldwide.

\section{KEYWORDS}

confirmatory factor analysis, emotional dysregulation, Inventory of Statements About Self-injury, Spanish clinical sample 


\section{1 | INTRODUCTION}

Nonsuicidal self-injury (NSSI) is any deliberate self-inflicted damage to the surface of the body with no suicidal intent and for purposes that are not socially sanctioned (Klonsky, Muehlenkamp, Lewis, \& Walsh, 2011). Rates of NSSI of around $20-30 \%$ have been reported in clinical adults in countries such as Turkey (e.g., Toprak et al., 2011) or Belgium (Claes, Norré, Van Assche, \& Bijttebier, 2014), and 30-50\% in clinical adolescents in American (Nock \& Prinstein, 2004) or German samples (Groschwitz et al., 2015). In Spain, Díaz de Neira et al. (2015) found that $21.7 \%$ of clinical adolescents self-injured, and Calvete et al. (2015) found that $32 \%$ of community adolescents had carried out severe NSSI. In addition, Pérez, Marco, and Cañabate (2018) found a higher rate around $37 \%$ in adults with an eating disorder diagnosis.

NSSI is comorbid with several mental disorders (In-Albon et al., 2013), especially mood disorders, anxiety, substance abuse disorders, and externalizing disorders (Nitkowski \& Petermann, 2011). In addition, the relationship between NSSI, eating disorders, and borderline personality disorder (BPD) has been well documented: Some studies have found that between $25.4 \%$ and $55.2 \%$ of eating disorder patients report NSSI (Claes et al., 2014; Claes, Vandereycken, \& Vertommen, 2003), and have reported a relationship between body image dissatisfaction and NSSI (Pérez et al., 2018). Moreover, literature shows that NSSI is present in $60-80 \%$ of patients with BPD (Gunderson \& Links, 2008), and 52\% of patients who met the NSSI disorder criteria also met the criteria for BPD (Selby, Kranzler, Fehling, \& Panza, 2015). NSSI it is a well-established risk factor for suicide (Klonsky et al., 2013).

Previous literature on NSSI (American Psychiatric Association, 2013; Klonsky \& Glenn, 2009; Nock \& Prinstein, 2004) has documented the importance of the functionality of these types of behaviors. In this context, a theoretical-empirical framework has been established for the functionality of nonsuicidal self-harm, postulating the existence of two main functions: Intrapersonal or automatic functions and interpersonal or social functions (Klonsky \& Glenn, 2009; Nock \& Prinstein, 2004).

Some of the most widely used self-report tools to assess NSSI include evaluations of several functions of selfharm. Some of them are the Functional Assessment of Self-Mutilation (FASM; Lloyd, Kelley, \& Hope 1997; Nock \& Prinstein, 2004, 2005), and the Inventory of Statements About Self-injury (ISAS; Klonsky \& Glenn, 2009). The FASM has the well-established psychometric properties of existing measures, but it does not assess functions related to sensation-seeking, coping with suicidal thoughts, or interpersonal boundaries (Klonsky, 2007). To address this weakness, Klonsky and Glenn (2009) designed the ISAS to assess NSSI functions with empirical evidence (Klonsky, 2007). The ISAS comprises two parts: Part I evaluates the frequency of 12 different types of NSSI behaviors: banging/hitting, biting, burning, carving, cutting, wound picking, needle-sticking, pinching, hair pulling, rubbing skin against rough surfaces, severe scratching, and swallowing chemicals; Part II contains 13 intrapersonal and interpersonal functions of NSSI. Each function is assessed by three items on a 3-point scale, ranging from 0 (not relevant) to 2 (very relevant). A higher score indicates a greater number of functions or motives for engaging in selfinjury.

In the original validation study of the ISAS, Klonsky and Glenn (2009) examined the psychometric properties of the functional scales in a sample of 235 American young adults from a college sample studying psychology, the majority Caucasian (41\%) or Asian (39\%) (mean $[M]$ age $=18.5$, standard deviation $[S D]=1.1$ ) who endorsed any of the NSSI behaviors. The authors carried out an exploratory factor analysis (EFA) with Promax Rotation to examine the structure of the functions, finding a robust two-factor solution. A first factor represented interpersonal functions (Autonomy, Interpersonal boundaries, Interpersonal influence, Peer-bonding, Revenge, Self-care, Sensation-seeking, and Toughness; eigenvalue = 5.9), and a second factor represented Intrapersonal functions (Affect regulation, Antidissociation, Antisuicide, Marking distress, and Self-punishment; eigenvalue = 1.6). These two factors are similar to the social and automatic functions obtained by Nock and Prinstein $(2004,2005)$, that refer to interpersonal and intrapersonal functions, respectively. Moreover, adequate coefficient alphas were obtained for both factors (interpersonal, $\alpha=.87$; intrapersonal, $\alpha=.80$ ). As for construct validity, Intrapersonal functions correlated higher with depression and suicidal ideation than interpersonal functions did, and 
intrapersonal functions were associated with the tendency to self-injure alone (Klonsky \& Glenn, 2009). In a 1-year test-retest study of the ISAS, Glenn and Klonsky (2011) found that the ISAS functional scales demonstrated good stability over 1 year $(0.60$ for the scale of the intrapersonal function and 0.82 for the scale of the interpersonal function). In addition, test-retest correlations ranged from 0.35 to 0.89 for specific functions.

In another study, Bildik, Somer, Kabukçu, Başay, and Özbaran (2012) translated the Inventory of the ISAS into Turkish and examined its psychometric properties in a stratified sample of 529 high school Turkish students (from 14 to 17 years old) who had performed at least one NSSI behavior. Authors carried out a confirmatory factor analysis (CFA) to examine the construct validity of the ISAS. The CFA results supported the internal construct validity of the two-factor model proposed in the second part of the inventory, with loadings between 0.55 and 0.79 for Interpersonal functions, and between 0.61 and 0.82 for intrapersonal functions. The internal consistency coefficients obtained for the intrapersonal and interpersonal function scores were adequate $(\alpha=.81$ and $\alpha=.86$, respectively). In addition, in the case of construct validity, intrapersonal and interpersonal functions were significantly related to suicide probability and distress. Finally, as for test-retest reliability, the correlations for intrapersonal and interpersonal functions were $r=0.58$ and $r=0.60$, respectively.

In the study of Kortge, Meade, and Tennant (2013), authors examined psychometric properties of the ISAS in a sample of 201 participants (ranging from 18 to 50 years old) who had engaged in NSSI in the previous year recruited from social network self-harm support groups, the majority from the United States (38\%), United Kingdom (36\%), Canada (9\%), and Australia (8\%). The majority of participants were Caucasian (88\%). The authors conducted an EFA forcing two factors to test the model proposed by Klonsky and Glenn (2009) using principal axis factoring. As expected, their results showed that the items loaded as expected onto the intrapersonal and interpersonal factors. Only the self-care scale loaded onto the intrapersonal factor instead of the interpersonal factor, which is consistent with the scale authors' original expectations, but not with their final results (Klonsky \& Glenn, 2009). The internal consistency coefficients obtained were adequate $(\alpha=.77$ for intrapersonal factor, including self-care, and $\alpha=.87$ for interpersonal factor).

Finally, in the most recent study focused on examining the structure of NSSI functions in a large American clinical sample of patients attending NSSI treatment for NSSI (predominately female, 89.4\%, and non-Hispanic white, 72.1\%), Klonsky, Glenn, Styer, Olino, and Washburn (2015) found, using an EFA, that the ISAS exhibited a robust two-factor structure representing both intrapersonal and interpersonal functions. Only item 17 (referred to self-care subscale) loaded on the Intrapersonal rather than the Interpersonal factor, unlike in the original Klonsky \& Glenn's study (Klonsky \& Glenn, 2009). Authors found excellent internal consistencies for both factors ( $\alpha=.88$ for intrapersonal factor and $\alpha=.89$ for interpersonal factor).

The ISAS has been used in a large number of studies with community and university samples to explore the functionality of NSSI (e.g., Bentley, Sauer-Zavala, \& Wilner, 2015; Klonsky \& Olino, 2008) and in clinical samples (e.g., Klonsky et al., 2015; Lindholm, Bjärehed, \& Lundh, 2011). The findings show that it is able to identify different profiles of self-injurers with different levels of severity, and they reveal the clinical utility of the instrument (Klonsky \& Olino, 2008). Given the documented utility of the instrument and the need to better understand the functionality of NSSI, further studies on the validation of this instrument are needed. However, to our knowledge, the ISAS has not been validated in Spanish participants with NSSI behaviors, and in previous studies conducted with clinical samples authors conducted EFA but not CFA. Given the high prevalence of NSSI in patients with a diagnosis of an eating disorder or BPD (Claes et al., 2014; Muehlenkamp, Ertelt, Miller, \& Claes, 2010), the main aim of the present study was to confirm the two-factor structure of the ISAS in a sample of participants with a diagnosis of an eating disorder, BPD, or both. We expected to find a two-factor-intrapersonal and interpersonal functions-structure, with adequate psychometric properties and good test-retest reliability for both Part I (functions) and Part II (types of NSSI). Moreover, we expected to find statistically significant positive correlations between the NSSI functions and emotional dysregulation, and on test-retest, both the types and functions of NSSI. As we evaluated patients undergoing treatment for eating disorders or BPD, despite significant test-retest correlations, we expected a reduction in scores on NSSI functions, emotional dysregulation, and eating disorders symptomatology. 


\section{2 | METHOD}

\section{1 | Participants}

A total of 370 participants with a diagnosis of an eating disorder or cluster B personality disorder were approached, and 355 voluntary participants completed the assessment for the present study $(89.4 \%$ women, $n=315$ and $11.3 \%$ men, $n=40)$. Most participants $(49.8 \%, n=164)$ were single, $40.7 \%(n=134)$ were married or living with a partner, and finally, 9.5\% ( $n=31$ ) were separated, divorced, or widowed. They had a mean age of 27.89 ( $S D=13.31$; ranged from 12 to 68 years). The majority completed secondary education $(53.5 \%, n=184)$, followed by those with primary education (27\%, $n=99$ ), higher education (18.6\%, $n=64)$, and no studies $(0.9 \%, n=3)$. As for diagnosis, $67.61 \%$ of the participants $(n=240)$ met the criteria for eating disorders, and $42.2 \%(n=136)$ met the criteria for BPD. In addition, $16.06 \%(n=57)$ met criteria for both ED and BPD.

\section{2 | Procedure}

The sample consisted of patients with a diagnosis of either eating disorders, BPD, or both, who were recruited individually at mental health outpatient services in various cities in Spain that provide multidisciplinary team treatment for eating disorders and personality disorders. The study procedure was approved by the ethical committees of the Valencia Ribera Hospital, and the Provincial Hospital of Castellon. Diagnoses were established by clinical psychologists at the hospital using the SCID-5-CV (First, Williams, Karg, \& Spitzer, 2015), and the exclusion criterion was having a moderate or severe intellectual disability. Thus, $67.61 \%$ of the participants $(n=240)$ met the criteria for eating disorders and $42.2 \%(n=136)$ met the criteria for BPD. In addition, $16.06 \%$ $(n=57)$ met criteria for both ED and BPD. Participants were given appropriate instructions to complete the assessment protocol, signed informed consent before the initial evaluation process, and they did not receive any kind of compensation for their participation. A university professor of Scientific English translated the ISAS to Spanish, and then an expert English-Spanish translator carried out a back-translation.

\section{3 | Instruments}

\subsection{1 | Inventory of Statements About Self-injury (Klonsky \& glenn, 2009)}

The presence of NSSI was evaluated using the ISAS-I and II parts. The first part of the inventory (ISAS-I) asks about the lifetime frequency of 12 different NSSI behaviors performed intentionally and without suicidal intent including banging/hitting, biting, burning, carving, cutting, wound picking, needle-sticking, pinching, hair pulling, rubbing skin against rough surfaces, severe scratching, and swallowing chemicals. Part II (ISAS-II) contains 13 intrapersonal and interpersonal functions of NSSI. Interpersonal functions refer to autonomy (When I self-harm, I am establishing that I am autonomous/independent), interpersonal boundaries (When I self-harm, I am creating a boundary between myself and others), interpersonal influence (When I self-harm, I am seeking care or help from others), peer-bonding (When I self-harm, I am fitting in with others), revenge (When I self-harm, I am trying to hurt someone close to me), self-care (When I self-harm, I am giving myself a way to care for myself -by attending to the wound), sensationseeking (When I self-harm, I am entertaining myself or others by doing something extremely), and toughness (When I self-harm, I am demonstrating I am tough or strong), and intrapersonal functions such as affect regulation (When I self-harm, I am calming myself down), antidissociation (When I self-harm, I am trying to feel something [as opposed to nothing] even if it is physical pain), antisuicide (When I self-harm, I am putting a stop to suicidal thoughts), marking distress (When I self-harm, I am creating a physical sign that I feel awful), and self-punishment (When I selfharm, I am expressing anger towards myself for being worthless or stupid). Each function is assessed by three items on a 3-point scale, ranging from 0 (not relevant) to 2 (very relevant). Good reliability coefficients were obtained for both interpersonal, $\alpha=.87$, and intrapersonal, $\alpha=.80$ factors, and in the 1-year test-retest reliability (Glenn $\&$ 
Klonsky, 2011). It also has descriptive features of NSSI, including the age of the first dysfunctional behavior and the date of the most recent episode. The ISAS-II assesses 13 NSSI intrapersonal and interpersonal functions. We found good internal consistency for both the intrapersonal $(\alpha=.83)$ and interpersonal functions $(\alpha=.83)$ in our sample.

\subsection{2 | Difficulties in emotional regulation scale}

This scale assesses different features of the emotion regulation process in adults (Gratz \& Roemer, 2004). The Spanish version is composed of 28 Likert-type items with five response levels, included in five subscales: (a) emotional lack of control (I experience my emotions as overwhelming and out of control); (b) life interference (When I'm upset, I have difficulty focusing on other things), (c) emotional inattention (I pay attention to how I feel), (d) emotional confusion (I am clear about my feelings), and (e) nonacceptance of emotions (When I'm upset, I become angry with myself for feeling that way). The DERS-28 offered good psychometric properties and high reliability for the global scale $(\alpha=.93$ ) and for the different subscales ( $\alpha$ from .79 to .91; Hervás \& Jódar, 2008). In the present study, the total scale showed excellent internal consistency, $\alpha=.93$ and from adequate to excellent reliability indexes for the different subscales: lack of control, $\alpha=.93$; nonacceptance of emotions, $\alpha=.89$; life interference, $\alpha=.89$; emotional inattention, $\alpha=.85$; and emotional confusion, $\alpha=.62$.

\subsection{3 | Eating Attitudes Test-40}

The Eating Attitudes Test-40 (EAT-40; Garner, Olmsted, Bohr, \& Garfinkel, 1982) was developed by Garner and Garfinkel (1979), and validated into Spanish by Castro, Toro, Salamero, and Guimerá (1991). It has been used in nonclinical samples as a general screening measure for disordered eating attitudes (Garner \& Garfinkel, 1979). It comprises 40 items in a Likert scale of 6 points (1-6) with a maximum score of 240 and a cut-off score of 30. Examples of items are "Weigh myself several times a day," "Prepare foods for others but do not eat what I cook," or "Become anxious before eating." In this study, we used the total score. The reported 1-month interval test-retest reliability coefficient of EAT-40 was 0.65 and internal consistency calculated by Cronbach alpha was acceptable, 0.70 (Castro et al., 1991). In our sample, we found an excellent internal consistency for the total score $(\alpha=.90)$.

\subsection{Statistical analyses}

First, sample characteristics were calculated through statistical descriptives. Second, descriptive statistics (M, SD, skewness, and Sk/Se, kurtosis, and Ku/Se) of the ISAS-II items were performed. Third, a CFA was performed for two models specified for the ISAS-II: The Klonsky and Glenn's (2009) original model (M1), and a model which included self-care in the Intrapersonal factor (M2). Because the ISAS-II is an ordinal scale (from 0 to 2), and because it was not possible to assume multivariate normality, the diagonally weighted least squares method, which is specifically designed for ordinal data with robust estimation was performed. Fit indices included: (a) the comparative fit index (CFI) and the Tucker-Lewis index (TLI), absolute indexes with values $\geq 0.90$ indicating acceptable fit and values $\geq 0.95$ indicating good model fit; and (b) the root mean square error of approximation (RMSEA), and the standardized root mean square residual (SRMR), indexes with values $\leq 0.08$ indicating acceptable model fit and values $\leq 0.05$ indicating good model fit (Hair, Black, Babin, Anderson, \& Tatham, 2006). For choosing the best of the two analyzed models (it was the M2), the expected cross-validation index (ECVI) was used (Schermellech-Engel \& Moosbrugger, 2003). These analyses were performed using the JASP free software.

Then, descriptive statistics, internal consistency, and construct validity (both convergent and discriminant validity) of the model with the best fit for the ISAS-II (M2; ISAS-II-M2) were calculated. Because Cronbach's alpha tends to underestimate reliability when there are few items and ordinal scales (as in the current study), the composite reliability (CR) of the ISAS-II-M2 factors (both intrapersonal and interpersonal) was also calculated (e.g., Brown, 2015). The convergent validity of the ISAS-II-M2 factors was reported with the average variance extracted 
(AVE). The discriminant validity of the ISAS-II-M2 was obtained by squaring the correlation $\left(R^{2}\right)$ between the factors. According to Hair et al. (2006), a value higher than 0.50 for the AVE indicates a good convergent validity, and an AVE of each variable higher to the $R^{2}$ between the factors indicates a good discriminant validity. To report the concurrent validity of the ISAS-II-M2 subscales and factors, the correlations with the difficulties in emotional regulation scale (DERS) were analyzed.

Finally, test-retest reliability for the ISAS-I was calculated. Because of the outliers in NSSI frequency, Spearman correlations were used to examine the stability of the types of NSSI between T1 and T2 (see Table 2), and Pearson correlations were used for a test-retest analysis of NSSI functions at T1-T2. Repeated measures analysis of variance (ANOVA) were used to compare NSSI functions, eating disorders symptomatology and emotional deregulation between T1 and T2. These analyses were performed using the SPSS version 23.0 software.

\section{3 | RESULTS}

Of the whole sample, $54.8 \%(n=194)$ self-injured. $52.6 \%$ had cut themselves at some time (from two to more than 500 times), and $70 \%$ of those who self-injured had done so more than five times. Other frequent self-injuries were banging (63.4\%), scratching (49\%), cutting superficially (39.9\%), taking dangerous substances (39.7\%), and biting (38.1\%).

\section{1 | Descriptive statistics of the ISAS-II subscales}

Table 1 shows the descriptive analysis of the ISAS-II items. It is notable the positive skewness of items 8,21 , and 34 (Peer-bonding subscale), 12, 25, and 38 (Revenge subscale), 20 (Sensation-seeking subscale), 30 (Self-care subscale), with scores higher than 2. Likewise, it is notable the kurtosis of items 8, 21, and 34 (Peer-bonding subscale), 12, 25, and 38 (Revenge subscale), 20 (Sensation-seeking subscale), 30 (Self-care subscale) with scores higher than 3.

\section{2 | Factor structure of the ISAS-II: Comparison of the Klonsky and Glenn's model and the model which included the Self-sare subscale in the intrapersonal factor}

A CFA for the Klonsky and Glenn's (2009) original ISAS-II (M1) and the model including the Self-case subscale in the intrapersonal factor (M2) were specified. Both models showed CFI and TLI indexes higher than .95, an RMSEA index lower than .050, and an SRMR lower than .080. M2 showed a $\chi^{2}$ lower than M1. The ECVI suggested that M2 (ISAS-II-M2) was preferable to M1 (Table 2). Figure 1 shows the model obtained for the ISAS-II-M2. All parameters were significant at the 0.05 level.

\section{3 | Means, standard deviations, and internal consistency of the model for the ISAS-II-M2}

Table 3 shows the means, SDs, Cronbach alphas of the ISAS-II-M2 scale and factors of the ISAS-II-M2 factors. Except in the case of the Self-care subscale, the Cronbach alphas satisfied the Devellis (2003) criterion for acceptable internal consistency ( $\alpha \geq .70$ ), with values between acceptable and strong (Ciccheti, 1994).

Although the Cronbach alpha of the Self-care subscale was below 0.70, the average inter-item correlation was 0.45 , which indicates an acceptable level of consistency (Nunnally \& Bernstein, 1994) and suggests that the items are well related to each other and might be suitable for measuring a single construct. The CR confirmed good internal consistency of both the interpersonal and intrapersonal factors of the ISAS-II-M2, which were 0.87 and 0.89 , respectively. 
TABLE 1 Descriptive statistics of the ISAS-II items

\begin{tabular}{|c|c|c|c|c|c|c|c|c|}
\hline Factor & Subscale & Item & M & $S D$ & $\begin{array}{l}\text { Skewness } \\
(S E=0.13)\end{array}$ & $\mathrm{Sk} / \mathrm{SE}$ & $\begin{array}{l}\text { Kurtosis } \\
(S E=0.26)\end{array}$ & $\mathrm{Ku} / \mathrm{SE}$ \\
\hline \multirow[t]{24}{*}{ Interpersonal } & Interpersonal boundaries & 2 & .50 & .74 & 1.11 & 8.54 & -0.27 & -1.04 \\
\hline & & 15 & .37 & .67 & 1.54 & 11.85 & .98 & 3.77 \\
\hline & & 28 & .37 & .65 & 1.54 & 11.85 & 1.06 & 4.08 \\
\hline & Self-care & 4 & .31 & .62 & 1.81 & 13.92 & 1.96 & 7.54 \\
\hline & & 17 & .62 & .83 & .81 & 6.23 & -1.07 & -4.12 \\
\hline & & 30 & .21 & .52 & 2.51 & 19.31 & 5.23 & 20.12 \\
\hline & Sensation-seeking & 7 & .32 & .63 & 1.78 & 13.69 & 1.79 & 6.88 \\
\hline & & 20 & .24 & .57 & 2.32 & 17.85 & 4.10 & 15.77 \\
\hline & & 33 & .34 & .67 & 1.73 & 13.31 & 1.46 & 5.62 \\
\hline & Peer-bonding & 8 & .26 & .58 & 2.13 & 16.38 & 3.26 & 12.54 \\
\hline & & 21 & .24 & .53 & 2.15 & 16.54 & 3.68 & 14.15 \\
\hline & & 34 & .26 & .57 & 2.09 & 16.08 & 3.16 & 12.15 \\
\hline & Interpersonal influence & 9 & .33 & .65 & 1.75 & 13.46 & 1.63 & 6.27 \\
\hline & & 22 & .38 & .67 & 1.51 & 11.62 & .86 & 3.31 \\
\hline & & 35 & .39 & .71 & 1.53 & 11.77 & .74 & 2.85 \\
\hline & Toughness & 10 & .35 & .65 & 1.63 & 12.54 & 1.26 & 4.85 \\
\hline & & 23 & .32 & .63 & 1.81 & 13.92 & 1.90 & 7.31 \\
\hline & & 36 & .34 & .66 & 1.72 & 13.23 & 1.47 & 5.65 \\
\hline & Revenge & 12 & .25 & .55 & 2.15 & 16.54 & 3.55 & 13.65 \\
\hline & & 25 & .22 & .53 & 2.37 & 18.23 & 4.57 & 17.58 \\
\hline & & 38 & .17 & .45 & 2.80 & 21.54 & 7.24 & 27.85 \\
\hline & Autonomy & 13 & .27 & .57 & 1.99 & 15.31 & 2.81 & 10.81 \\
\hline & & 26 & .31 & .63 & 1.83 & 14.08 & 1.96 & 7.54 \\
\hline & & 39 & .31 & .63 & 1.83 & 14.08 & 1.95 & 7.50 \\
\hline \multirow[t]{15}{*}{ Intrapersonal } & Affect regulation & 1 & .70 & .84 & .62 & 4.77 & -1.30 & -5.00 \\
\hline & & 14 & .79 & .90 & .43 & 3.31 & -1.64 & -6.31 \\
\hline & & 27 & .84 & .93 & .32 & 2.46 & -1.78 & -6.85 \\
\hline & Self-punishment & 3 & .66 & .86 & .71 & 5.46 & -1.26 & -4.85 \\
\hline & & 16 & .79 & .92 & .43 & 3.31 & -1.67 & -6.42 \\
\hline & & 29 & .84 & .92 & .32 & 2.46 & -1.75 & -6.73 \\
\hline & Antidissociation & 5 & .58 & .82 & .90 & 6.92 & -0.91 & -3.50 \\
\hline & & 18 & .45 & .74 & 1.30 & 10.00 & .09 & 0.35 \\
\hline & & 31 & .37 & .67 & 1.58 & 12.15 & 1.04 & 4.00 \\
\hline & Antisuicide & 6 & .52 & .79 & 1.07 & 8.23 & -0.55 & -2.12 \\
\hline & & 19 & .47 & .75 & 1.22 & 9.38 & -.11 & -0.42 \\
\hline & & 32 & .45 & .72 & 1.27 & 9.77 & .11 & 0.42 \\
\hline & Marking distress & 11 & .51 & .77 & 1.11 & 8.54 & -.39 & -1.50 \\
\hline & & 24 & .56 & .79 & .96 & 7.38 & -.71 & -2.73 \\
\hline & & 37 & .64 & .84 & .76 & 5.85 & -1.17 & -4.50 \\
\hline
\end{tabular}

Note: $N=355$.

Abbreviations: ISAS, Inventory of Statements About Self-injury; M, mean; SD, standard deviation; SE, standard error. 
TABLE 2 Fit indexes for the two models analyzed in this study

\begin{tabular}{lllllllllll} 
Model & $\chi^{2}$ & $\Delta \chi^{2}$ & $d f$ & $p$ Value & CFI & TLI & RMSEA [90\% Cl] & RMSEA $\leq 0.05$ & SRMR & ECVI \\
\hline M1 & 101.561 & & 62 & .001 & .991 & .989 & $.042[.027,0.057]$ & .792 & .065 & .451 \\
M2 & 88.435 & 13.13 & 62 & $<0.001$ & .994 & .993 & $.035[.016,0.050]$ & .947 & .061 & .414 \\
\hline
\end{tabular}

Note: M1 = The Klonsky and Glenn's (2009) model; M2 = The model which included the Self-care subscale in the intrapersonal factor of the ISAS-II.

Abbreviations: $\mathrm{CFI}$, comparative fit index; $\mathrm{Cl}$, condfidence interval; ECVI, expected cross-validation index; RMSEA, root mean square error of approximation; SRMR, standardized root mean square residual; TLI, Tucker-Lewis index.

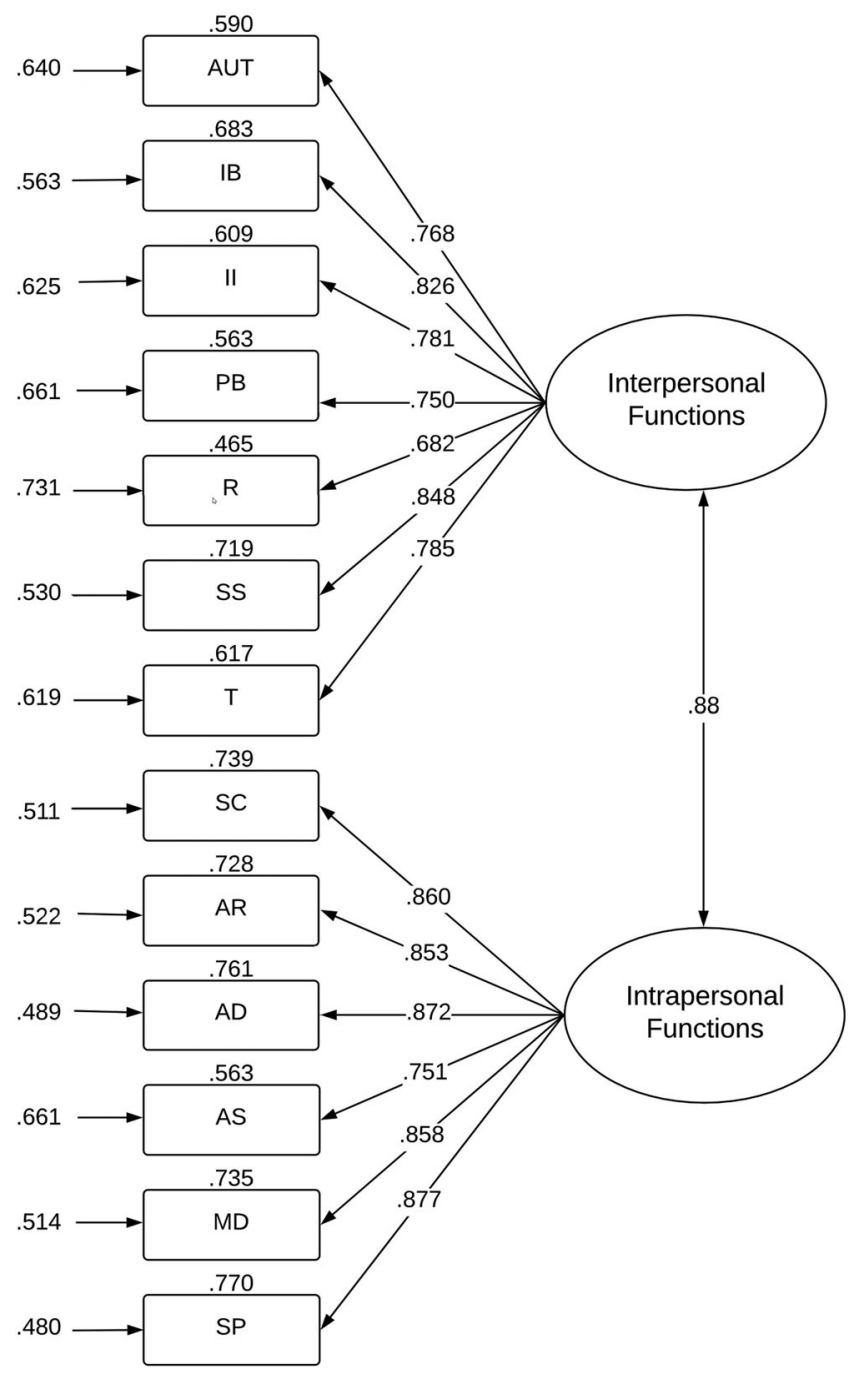

FIGURE 1 Model for the ISAS-II obtained in the current study (M2). Note: Values at the top of each rectangle are R2; values at the left of each rectangle are errors. A, autonomy; AD, antidissociation; AR, affect regulation; AS, antisuicide; IB, interpersonal boundaries; II, interpersonal influence; MD, marking distress; PB, peer-bonding; R, revenge; SC, self-care; SP, self-punishment; SS, sensation-seeking; T, toughness 
TABLE 3 Means, standard deviations, internal consistency $(n=355)$ and test-retest correlations of the ISAS-II $(n=123)$

\begin{tabular}{|c|c|c|c|c|c|c|c|}
\hline & & \multicolumn{2}{|l|}{ T1 } & \multirow{2}{*}{$\begin{array}{l}\text { Cronbach } \\
\text { alpha }\end{array}$} & \multicolumn{2}{|l|}{ T2 } & \multirow{2}{*}{$\begin{array}{l}\text { Correlation }(r) \\
\text { T1-T2 function } \\
\text { scales }\end{array}$} \\
\hline & & $M$ & $S D$ & & $S D$ & $M$ & \\
\hline \multirow[t]{8}{*}{ Factor I } & Interpersonal & .83 & 1.16 & .93 & .38 & .74 & $.75^{* * *}$ \\
\hline & Sensation-seeking & .92 & 1.59 & .77 & .39 & .87 & $.65^{* * *}$ \\
\hline & Autonomy & .92 & 1.61 & .79 & .44 & 1.17 & $.50^{* * *}$ \\
\hline & Interpersonal boundaries & 1.26 & 1.77 & .79 & 67 & 1.37 & $.71^{* * *}$ \\
\hline & Interpersonal influence & 1.12 & 1.76 & .80 & .34 & .94 & $.53^{* * *}$ \\
\hline & Peer-bonding & .77 & 1.46 & .80 & .21 & .74 & $.50^{* * *}$ \\
\hline & Toughness & 1.04 & 1.80 & .85 & .54 & 1.21 & $.72^{* * *}$ \\
\hline & Revenge & .65 & 1.40 & .86 & .31 & 1.04 & $.68^{* * *}$ \\
\hline \multirow[t]{7}{*}{ Factor II } & Intrapersonal & 1.88 & 2.01 & .93 & 1.09 & 1.65 & $.74^{* * *}$ \\
\hline & Self-care & 1.18 & 1.66 & .67 & .63 & 1.17 & $.71^{* * *}$ \\
\hline & Antidissociation & 1.46 & 2.05 & .80 & .89 & 1.66 & $.56^{* * *}$ \\
\hline & Antisuicide & 1.26 & 2.05 & .78 & .89 & 1.75 & $.49^{* * *}$ \\
\hline & Marking distress & 1.75 & 2.20 & .85 & 1.02 & 1.79 & $.69^{* * *}$ \\
\hline & Self-punishment & 2.33 & 2.54 & .90 & 1.6 & 2.4 & $.80^{* * *}$ \\
\hline & Affect regulation & 2.41 & 2.58 & .90 & 1.5 & 2.3 & $.71^{* * *}$ \\
\hline
\end{tabular}

Abbreviations: $M$, mean; $S D$, standard deviation.

${ }^{* * *} p<.001$.

\section{4 | Construct validity of the ISAS-II-M2}

Convergent validity. The AVE values for the interpersonal factor, 0.61 , and intrapersonal factor, 0.72 , of the ISAS-II-M2 indicated good convergent validity (Hair et al., 2006). Discriminant validity. The squared correlation between the ISAS-II-M2 factors, $R^{2}=.64$, was lower than the AVE value for the intrapersonal factor and slightly higher than the AVE value for the Interpersonal factor. These data indicate good discriminant validity (Hair et al., 2006).

\section{5 | Concurrent validity of the ISAS-II-M2}

To report the concurrent validity of the ISAS-II-M2, the correlations between the scale and its factors and the DERS were calculated. The ISAS-II-M2 scale and factors showed positive and significant correlations with the DERS (Table 4) in the expected direction, given what the scales are supposed to assess.

\section{6 | Test-retest validity}

Test-retest reliabilities of the ISAS NSSI types and functional sections were calculated from data from the 123 patients who were evaluated at both T1 and at 7 months (T2) (Table 3 and 5). Spearman correlations ranged from .23 (pulling hair) to .78 (cutting), with biting $(\rho=0.66)$, carving $(\rho=0.64)$, rubbing skin $(\rho=.60)$, and banging/hitting $(\rho=0.56)$ being the highest. We have to note that two correlations were nonsignificant, given that burning and sticking needles were hardly present at T2 (Table 5). As for the stability of the NSSI functions over time, we found that the Pearson correlations were statistically significant for the different functionalities, ranging from .50 (Autonomy) to .72 (Toughness) for the Interpersonal scales, and from .56 (Antidissociation) to .80 (Self-punishment) 


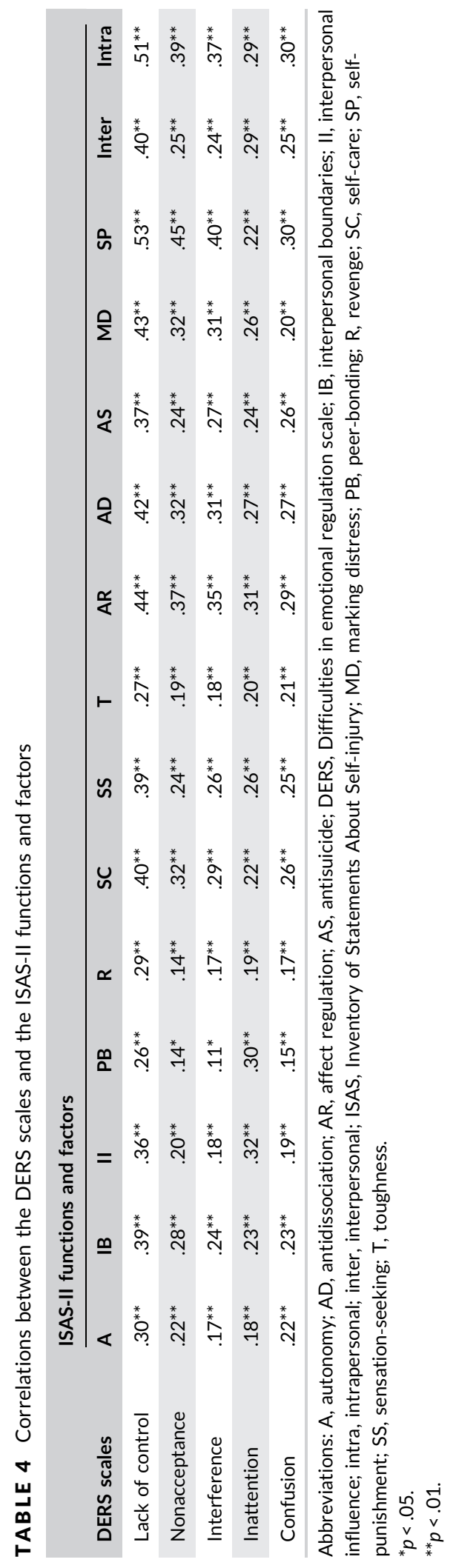


TABLE 5 Descriptive statistics and 7-month test-retest Spearman correlations for the ISAS behavioral scales $(n=123)$

\begin{tabular}{|c|c|c|c|c|c|}
\hline \multirow[b]{2}{*}{ NSSI types } & \multicolumn{2}{|l|}{ T1 } & \multicolumn{2}{|l|}{ T2 } & \multirow{2}{*}{$\begin{array}{l}\text { Correlation }(r) \text { T1- } \\
\text { T2 NSSI types }\end{array}$} \\
\hline & M & $S D$ & M & $S D$ & \\
\hline Cutting & 21.06 & 83.84 & 5.00 & 32.56 & $.78^{* * *}$ \\
\hline Biting & 8.46 & 43.13 & 1.72 & 10.49 & $.66^{* * *}$ \\
\hline Burning & 2.19 & 18.73 & .00 & .00 & - \\
\hline Carving & 19.92 & 85.44 & 4.93 & 45.26 & $.64^{* * *}$ \\
\hline Pinching & 13.35 & 86.09 & 8.42 & 57.78 & $.47^{* * *}$ \\
\hline Pulling hair & 11.48 & 58.55 & 1.21 & 9.37 & $.23^{*}$ \\
\hline Scratching & 22.29 & 82.99 & 5.33 & 31.64 & $.38^{* * *}$ \\
\hline Banging/hitting & 20.06 & 71.24 & 3.43 & 20.89 & $.56^{* * *}$ \\
\hline Interfering with wounds & 16.00 & 70.51 & 2.54 & 15.80 & $.36^{* * *}$ \\
\hline Rubbing skin & 8.21 & 60.24 & 4.27 & 5.17 & $.60^{* * *}$ \\
\hline Sticking needles & 3.65 & 38.00 & .01 & .09 & n.s. \\
\hline Swallowing chemicals & 34.46 & 140.10 & .27 & 1.42 & $.42^{* * *}$ \\
\hline
\end{tabular}

Abbreviations: ISAS, Inventory of Statements About Self-injury; M, mean; NSSI, nonsuicidal self-injury; n.s., not significant; $S D$, standard deviation.

${ }^{*} p<.05$.

${ }^{* * *} p<.001$.

for the intrapersonal functions, and showing similar stability for the Interpersonal and intrapersonal functions $(0.75$ and 0.74, respectively). Moreover, we found a high correlation for affect regulation between T1 and T2 ( $r=.71$ ), which is the most common function of NSSI (Klonsky, 2007; Table 3).

In addition, we conducted repeated-measures ANOVA for intrapersonal and interpersonal functions, emotional dysregulation and eating disorders symptomatology at both T1 and T2. Results showed statistically significant differences between T1 and T2 in both intrapersonal and interpersonal functions of NSSI, with lower levels of intrapersonal functions at T2 $(F=4.14 ; p=.044 ; \mathrm{T} 1 \mathrm{M}=1.41, \mathrm{DT}=1.83 ; \mathrm{T} 2 \mathrm{M}=1.18 ; \mathrm{DT}=1.78)$. Similar results were found for interpersonal functions $(F=4.14 ; p=.044 ; \mathrm{T} 1 \mathrm{M}=.57 \mathrm{DT}=0.90 ; \mathrm{T} 2 \mathrm{M}=.45 ; \mathrm{DT}=.82)$, eating disorders symtomatology $(F=14.81 ; p=.000 ; \mathrm{T} 1 \mathrm{M}=40.97 \mathrm{DT}=24.32 ; \mathrm{T} 2 \mathrm{M}=34.80 ; \mathrm{DT}=27.45)$, and emotional dysregulation ( $F=4.57 ; p=.035 ; \mathrm{T} 1 \mathrm{M}=24.25 \mathrm{DT}=9.97 ; \mathrm{T} 2 \mathrm{M}=22.83 ; \mathrm{DT}=10.28)$. These results showed similar reductions in NSSI functions than in emotional dysregulation and in eating disorder psychopathology of patients with ED between T1 and T2.

\section{DISCUSSION}

The main purpose of the present study was to analyze the psychometric properties of the ISAS-II (Klonsky \& Glenn, 2009) in a Spanish sample of 355 clinical patients with eating disorders or BPD, and to analyze the test-retest validity of the ISAS-I. Two models for the ISAS-II were performed: The Klonsky and Glenn's (2009) original model (M1, which include the Self-care subscale in the interpersonal factor of the ISAS-II) and a model in which the Selfcare subscale was included in the intrapersonal factor of the ISAS-II. M2 showed to be preferable to M1 and good internal consistency, construct validity (both convergent and discriminant validity), and concurrent validity was shown by correlations with the DERS scale. Moreover, we expected to find adequate test-retest reliability between 
parts I and II of the ISAS, despite the reduction in NSSI functions, eating disorder symptoms and emotional dysregulation after the psychological intervention.

\section{1 | Structural validity of the ISAS-II}

The model that included the Self-care subscale in the Intrapersonal factor was preferable to the Klonsky and Glenn's (2009) original model. The inclusion of the Self-care subscale (self-injuring to create a physical wound that one can care for more easily than one's emotional distress) in the intrapersonal factor might be explained by the fact that it seems to refer to a way to manage emotional distress through care for a physical wound. In fact, Klonsky and Glenn (2009), in their original work, highlighted that although self-care would have fit better as an intrapersonal function, this subscale loaded more highly on the interpersonal factor. Moreover, the authors indicated that the difference between the self-care loadings in the interpersonal and intrapersonal factors was very low (.41 and .33, respectively). Therefore, the authors suggested that future studies should examine the best conceptualization for this subscale, as either an intrapersonal or interpersonal function. Similar results to ours were found by Kortge et al. (2013) and Klonsky et al. (2015), who found that item 17 (referred to self-care) loaded on the intrapersonal factor.

The model obtained in the present study has both similar and different characteristics from the studies by Klonsky and Glenn (2009), Bildik, Somer, Basay, Basay, and Özbaran (2013), Kortge et al. (2013), and Klonsky et al. (2015). As in these studies, we obtained a two-factor model, confirming the structure of the ISAS-II. However, a significant difference between our results and those of Klonsky and Glenn (2009) and Bildik et al. (2013) is that we obtained a model in which the Self-care subscale was included in the intrapersonal factor, which can be explained, as noted above, by the different samples studied. Klonsky and Glenn (2009) and Bildik et al. (2013) evaluated NSSI in normal student populations, whereas our study and those by Kortge et al. (2013) and Klonsky et al. (2015) evaluated NSSI in clinical samples or in specific samples of NSSI participants seeking help. The greater severity of these latter samples may explain the differences in the results. Results suggested that eating disorder and patients with BPD self-injure due to both intrapersonal and interpersonal motives. Together, all of the functions of the ISAS-II could be related to the sense of control that is sometimes associated with NSSI, which is common in eating disorder and borderline patients.

\subsection{Internal consistency of the ISAS-II-M2}

Although the Self-care subscale showed a Cronbach alpha below .70, its average inter-item correlation indicates an acceptable level of consistency (Nunnally \& Bernstein, 1994) and suggests that the items on this subscale are strongly related to each other and, therefore, might be suitable for measuring a single construct. All the other subscales and both factors of the ISAS-II obtained Cronbach alphas higher than .70, satisfying the Devellis (2003) criterion for acceptable internal consistency. Moreover, the CR confirmed good internal consistency of both the interpersonal and intrapersonal factors of the ISAS-II-M2. These results, consistent with the findings of Klonsky and Glenn (2009) and Bildik et al. (2013), indicate that the ISAS-II-M2 is a reliable scale.

\section{3 | Construct validity of the ISAS-II model obtained in the present study}

The ISAS-II-M2 showed good convergent validity, and so it can be assumed that the subscales that make up each of the ISAS-II factors are measuring a particular construct. Specifically, the Autonomy, Interpersonal boundaries, Interpersonal influence, Peer-bonding, Revenge, Sensation-seeking, and Toughness scales measure interpersonal functions of NSSI, and the Self-care, Affect regulation, Antidissociation, Antisuicide, Making distress, and Self-punishment scales measure intrapersonal functions of NSSI. 
Regarding the discriminant validity, the result obtained requires a reflection because the squared correlation between the ISAS-II-M2 factors was lower than the AVE value for the intrapersonal factor and slightly higher than the AVE value for the Interpersonal factor. This result might be explained by the inclusion of the Self-care subscale in the Intrapersonal factor in the present study. This question requires further research.

\subsection{Concurrent validity of the ISAS-II-M2}

The ISAS-II-M2 showed an adequate fit with strong, positive correlations with the DERS scale: The greater the NSSI functions, the higher the emotional dysregulation. This result is in line with previous empirical evidence about the association between NSSI behaviors and emotional dysregulation (e.g., Fox et al., 2015; Gratz \& Roemer, 2004).

\section{5 | Test-retest reliability of the ISAS}

First, this is one of the few studies that have explored the temporal stability of the NSSI functions of the ISAS over time, finding, as in previous studies (Bildik et al., 2012; Glenn \& Klonsky, 2011), that the ISAS behavioral and functional scales demonstrate good test-retest stability despite reduction in psychopathological symptoms due to intervention. Moreover, these results indicate that the frequencies of the different types and functions of NSSI are relatively stable. In our study, the most stable types of NSSI were cutting, biting, and carving. Cutting is the most frequent and severe type of NSSI, and in previous research, it has been found to be the ISAS NNSI type with the highest consistency over time. These results are similar to those of Glenn and Klonsky (2011) and Bildik et al. (2012).

In our sample, we found that patients receiving psychotherapy to treat their psychopathology, although continued to use NSSI as a way to regulate distressing emotional states or self-punish themselves at follow-up, they showed a diminished NSSI functionality at follow-up. These results may indicate that although NSSI constitutes a strongly effective way to manage distress and self-punish, is reduced due to therapeutic interventions. Indeed, we found the same trend for reduction of emotional dysregulation or eating disorder symptoms at 7 months. Thus, psychotherapeutic strategies given to patients seem to serve to reduce these dysfunctional behaviors. Despite these results, we found that both intrapersonal and interpersonal functions showed high correlations and thus stability over time. Some of the most stable intrapersonal functions over time were self-punishment and affect regulation, which is some of the most frequent functions endorsed by patients (e.g., Klonsky, 2007; Pérez et al. 2018). Similar results were found for interpersonal functions such as toughness and interpersonal boundaries, which showed the highest stability at 7 months.

\section{5 | STRENGTHS, LIMITATIONS OF THE PRESENT STUDY, AND SUGGESTIONS FOR FURTHER RESEARCH}

To our knowledge, only five studies have examined the psychometric properties or the factorial structural of the ISAS in community samples of students (Bildik et al., 2012; Glenn \& Klonsky, 2011; Klonsky \& Glenn, 2009) or in participants with NSSI behavior (Klonsky et al., 2015; Kortge et al., 2013). However, this is the first study that has adapted and examined the factorial structure of the ISAS in a clinical sample of Spanish participants with mental or personality disorders. Moreover, there are very few valid instruments to assess NSSI, an increasing behavior problem that requires valid and reliable measures available worldwide. In addition, we used a broad initial sample that allowed us to test the factorial structure of the ISAS.

Despite the value of the current work in expanding valid assessments of NSSI in clinical samples, the study presents some limitations. Although our sample was composed of 355 participants with a diagnosis of an ED or $\mathrm{BPD}$, the results cannot be generalized to other clinical samples. It would be important to test the invariance of the 
factorial structure of the ISAS-II across patients without comorbidity. In the present study, the small subsample size of patients diagnosed with BPD suggested not to test measurement invariance.

Moreover, because the Self-care subscale was found to be related to Intrapersonal functions in this study and in the Kortge et al. (2013) study, but not in the original study by Klonsky and Glenn (2009), future studies are needed to clarify the role of this function. Finally, one of our aims was to test the stability of the ISAS functions over time, but we did not assess variables affecting this stability. Longitudinal studies using the Ecological Momentary Assessment to identify micro longitudinal and longitudinal changes in NSSI and possible moderating variables in this change would shed light on this issue.

\section{CONFLICT OF INTERESTS}

The authors declare that there are no conflict of interests.

\section{ORCID}

Sandra Pérez (D) http://orcid.org/0000-0003-1210-8732

Joaquín García-Alandete (iD) http://orcid.org/0000-0003-0769-4060

\section{REFERENCES}

American Psychiatric Association (2013). Diagnostic and statistical manual of mental disorders (5th ed.). Arlington, VA: Author

Bentley, K. H., Sauer-Zavala, S., \& Wilner, J. (2015). The unique contributions of distinct experiential avoidance domains to severity and functionality of non-suicidal self-injury. Journal of Experimental Psychopathology, 6, 40-57. https://doi.org/ 10.5127/jep.040613

Bildik, T., Somer, O., Kabukcu Basay, B., Basay, O., \& Ozbaran, B. (2012). Kendine zarar verme davranısı degerlendirme envanterinin Türkce formunun geçerlik ve guvenilirlik çalısması [The validity and reliability study of the Turkish version of self-injurious behaviour assessment inventory]. Türk Psikiyatri Dergisi, 23, 49-57. https://doi.org/10.5080/u6901

Bildik, T., Somer, O., Basay, B. K., Basay, Ö., \& Özbaran, B. (2013). The validity and reliability of the Turkish version of the inventory of statements about self-injury. Turk Psikiyatri Dergisi, 24(1), 1-9.

Brown, T. A. (2015). Confirmatory factor analysis for applied research. New York, NY: Guilford Press.

Castro, J., Toro, J., Salamero, M., \& Guimerá, E. (1991). The Eating Attitudes Test: Validation of the Spanish version. Evaluación Psicológica, 7(2), 175-190.

Calvete, E., Orue, I., Aizpuru, L., \& Brotherton, H. (2015). Prevalence and functions of non-suicidal self-injury in Spanish adolescents. Psicothema, 27(3), 223-228. https://doi.org/10.7334/psicothema2014.262

Cicchetti, D. V. (1994). Guidelines, criteria, and rules of thumb for evaluating normed and standardized assessment instruments in psychology. Psychological Assessment, 6(4), 284-290. https://doi.org/10.1037/1040-3590.6.4.284

Claes, L., Norré, J., Van Assche, L., \& Bijttebier, P. (2014). Non-suicidal self-injury (functions) in eating disorders: Associations with reactive and regulative temperament. Personality and Individual Differences, 57, 65-69. https://doi. org/10.1016/j.paid.2013.09.022

Claes, L., Vandereycken, W., \& Vertommen, H. (2003). Eating-disordered patients with and without self-injurious behaviours: A comparison of psychopathological features. European Eating Disorders Review, 11(5), 379-396. https://doi. org/10.1002/erv.510

Devellis, R. F. (2003). Scale development: Theory and applications (2nd ed.). Thousand Oaks, CA: Sage.

Díaz de Neira, M., García-Nieto, R., de León-Martínez, V., Fominaya, M. P., Baca-García, E., \& Carballo, J. J. (2015). Prevalencia y funciones de los pensamientos y conductas autoagresivas en una muestra de adolescentes evaluados en consultas externas de salud mental [Prevalence and functions of self-injurious thoughts and behaviors in a sample of Spanish adolescents assessed in mental health outpatient departments]. Revista de Psiquiatría y Salud Mental, 8(3), 137-145. https://doi.org/10.1016/j.rpsm.2013.09.003

First, M. B., Williams, J. B. W., Karg, R. S., \& Spitzer, R. L. (2015). Structured clinical interview for DSM-5-Research version (SCID-5 for DSM-5, research version; SCID-5-RV), Arlington, VA: American Psychiatric Association.

Fox, K. R., Franklin, J. C., Ribeiro, J. D., Kleiman, E. M., Bentley, K. H., \& Nock, M. K. (2015). Meta-analysis of risk factors for nonsuicidal self-injury. Clinical Psychology Review, 42, 156-167. https://doi.org/10.1016/j.cpr.2015.09.002 
Garner, D. M., \& Garfinkel, P. E. (1979). The Eating Attitudes Test: An index of the symptoms of anorexia nervosa. Psychological Medicine, 9(02), 273-279. https://doi.org/10.1017/S0033291700030762

Garner, D. M., Olmsted, M. P., Bohr, Y., \& Garfinkel, P. E. (1982). The eating attitudes test: Psychometric features and clinical correlates. Psychological Medicine, 12(04), 871-878. https://doi.org/10.1017/S0033291700049163

Glenn, C. R., \& Klonsky, E. D. (2011). One-year test-retest reliability of the Inventory of Statements About Self-Injury (ISAS). Assessment, 18(3), 375-378. https://doi.org/10.1177/1073191111411669

Gratz, K. L., \& Roemer, L. (2004). Multidimensional assessment of emotion regulation and dysregulation: Development, factor structure, and initial validation of the difficulties in emotion regulation scale. Journal of Psychopathology and Behavioral Assessment, 26(1), 41-54. https://doi.org/10.1023/B:JOBA.0000007455.08539.94

Groschwitz, R. C., Plener, P. L., Schumacher, T., Stoehr, R., Boege, I., \& Kaess, M. (2015). The situation of former adolescent self-injurers as young adults: A follow-up study. BMC Psychiatry, 15(1), 160. https://doi.org/10.1186/ s12888-015-0555-1

Gunderson, J. G., \& Links, P. S. (2008). The borderline diagnosis. In Gunderson, J. G., \& Links, P. S. (Eds.), Borderline personality disorder: A clinical guide (2nd, pp. 1-28). Washington: American Psychiatric Publishing.

Hair, J. F., Black, W. C., Babin, B. J., Anderson, R. E., \& Tatham, R. L. (2006). Multivariate data analysis. New Jersey: Pearson International Edition.

Hervás, G., \& Jódar, R. (2008). Adaptación al castellano de la Escala de Dificultades en la Regulación Emocional [Spanish adaptation of the Difficulties in Emotional Regulation Scale]. Clínica y Salud, 19(2), 139-156.

In-Albon, T., Bürli, M., Ruf, C., \& Schmid, M. (2013). Non-suicidal self-injury and emotion regulation: A review on facial emotion recognition and facial mimicry. Child and Adolescent Psychiatry and Mental Health, 7(1), 5. https://doi.org/10. 1186/1753-2000-7-5

Klonsky, E. D. (2007). The functions of deliberate self-injury: A review of the evidence. Clinical Psychology Review, 27, 226-239. https://doi.org/10.1016/j.cpr.2006.08.002

Klonsky, E. D., \& Glenn, C. R. (2009). Assessing the functions of non-suicidal self-injury: Psychometric properties of the Inventory of Statements About Self-injury (ISAS). Journal of Psychopathology and Behavioral Assessment, 31(3), $215-219$. https://doi.org/10.1007/s10862-008-9107-z

Klonsky, E. D., May, A. M., \& Glenn, C. R. (2013). The relationship between nonsuicidal self-injury and attempted suicide: Converging evidence from four samples. Journal of Abnormal Psychology, 122(1), 231-237. https://doi.org/10.1037/ a0030278

Klonsky, E. D., Glenn, C. R., Styer, D. M., Olino, T. M., \& Washburn, J. J. (2015). The functions of nonsuicidal self-injury: Converging evidence for a two-factor structure. Child and Adolescent Psychiatry and Mental Health, 9, 44. https://doi.org/ 10.1186/s13034-015-0073-4

Klonsky, E. D., Muehlenkamp, J., Lewis, S. P., \& Walsh, B. (2011). Nonsuicidal self-injury. Göttingen: Hogrefe Publishing.

Klonsky, E. D., \& Olino, T. M. (2008). Identifying clinically distinct subgroups of self-injurers among young adults: A latent class analysis. Journal of Consulting and Clinical Psychology, 76(1), 22-27. https://doi.org/10.1037/0022-006X.76.1.22

Kortge, R., Meade, T., \& Tennant, A. (2013). Interpersonal and intrapersonal functions of deliberate self-harm (DSH): A psychometric examination of the Inventory of Statements About Self-Injury (ISAS) scale. Behaviour Change, 30(1), 24-35. https://doi.org/10.1017/bec.2013.3

Lindholm, T., Bjärehed, J., \& Lundh, L. G. (2011). Functions of non-suicidal self-injury among young women in residential care: A pilot study with the Swedish version of the inventory of statements about self-injury. Cognitive Behaviour Therapy, 40, 183-189. https://doi.org/10.1080/16506073.2011.565791

Lloyd, E. E., Kelley, M. L., \& Hope, T. (1997, April). Self-mutilation in a community sample of adolescents: Descriptive characteristics and provisional prevalence rates. In Annual Meeting of the Society for Behavioral Medicine, New Orleans, LA.

Muehlenkamp, J. J., Ertelt, T. W., Miller, A. L., \& Claes, L. (2010). Borderline personality symptoms differentiate non-suicidal and suicidal self-injury in ethnically diverse adolescent outpatients. The Journal of Child Psychology and Psychiatry, 52(2), 148-155. https://doi.org/10.1111/j.1469-7610.2010.02305.x

Nitkowski, D., \& Petermann, F. (2011). Selbstverletzendes Verhalten und komorbide psychische Störungen: Ein Überblick. Fortschritte der Neurologie · Psychiatrie, 79(1), 9-20. https://doi.org/10.1055/s-0029-1245772

Nock, M. K., \& Prinstein, M. J. (2004). A functional approach to the assessment of self-mutilative behavior. Journal of Consulting and Clinical Psychology, 72(5), 885-890. https://doi.org/10.1037/0022-006X.72.5.885

Nock, M. K., \& Prinstein, M. J. (2005). Contextual features and behavioral functions of self-mutilation among adolescents. Journal of Abnormal Psychology, 114(1), 140-146. https://doi.org/10.1037/0021-843X.114.1.140

Nunnally, J. C., \& Bernstein, I. H. (1994). Psychometric theory (3rd ed.). New York, NY: McGraw Hill.

Pérez, S., Marco, J. H., \& Cañabate, M. (2018). Non-suicidal self-injury in patients with eating disorders: Prevalence, forms, functions, and body image correlates. Comprehensive Psychiatry, 84, 32-38. https://doi.org/10.1016/j.comppsych.2018. 04.003 
Schermellech-Engel, K., \& Moosbrugger, H. (2003). Evaluating the fit of structural equation models: Tests of significance and sescriptive goodness-of-fit measures. Methods of Psychological Research Online, 8(2), 23-74.

Selby, E. A., Kranzler, A., Fehling, K. B., \& Panza, E. (2015). Nonsuicidal self-injury disorder: The path to diagnostic validity and final obstacles. Clinical Psychology Review, 38, 79-91. https://doi.org/10.1016/j.cpr.2015.03.003

Toprak, S., Cetin, I., Guven, T., Can, G., \& Demircan, C. (2011). Self-harm, suicidal ideation and suicide attempts among college students. Psychiatry Research, 187(1-2), 140-144. https://doi.org/10.1016/j.psychres.2010.09.009

How to cite this article: Pérez S, García-Alandete J, Cañabate M, Marco JH. Confirmatory factor analysis of the Inventory of Statements About Self-Injury in a Spanish clinical sample. J. Clin. Psychol. 2020;76:102-117. https://doi.org/10.1002/jclp.22844 